\title{
Use of an Elastomeric Knee Brace in Patellofemoral Pain Syndrome: Short-Term Results
}

\author{
Francesco Mattia Uboldi ${ }^{1}$ Paolo Ferrua ${ }^{2}$ Daniele Tradati ${ }^{2}$ Pietro Zedde ${ }^{3} \quad$ jim Richards $^{4}$ \\ Andrea Manunta ${ }^{1}$ Massimo Berruto ${ }^{2}$
}

1 Department of Orthopaedics, University of Sassari, Sassari, Italy

2 Department of Knee Surgery, Gaetano Pini Hospital, Milan, Italy

3 Orthopaedic and Traumatology Unit, Nuoro Hospital, Nuoro, Italy

${ }^{4}$ Allied Health Research Unit, School of Health Sciences, College of Health and Wellbeing, University of Central Lancashire, Lancashire, United Kingdom

Joints 2018;6:85-89.
Address for correspondence Francesco Mattia Uboldi, MD, Department of Orthopaedics, University of Sassari, Viale San Pietro 43/B, 07100 Sassari, Italy (e-mail: fraubo@gmail.com).

\begin{abstract}
Keywords

- knee joint

- patellofemoral pain syndrome

- braces

- athletes

Purpose This article verifies the effectiveness of a new brace on patellofemoral pain syndrome (PFPS) in adjunct to a specifically developed rehabilitation program.

Methods Two groups of 30 patients with PFPS were prospectively and randomly allocated to a rehabilitation protocol, with (group A) or without (group B) the use of a specific brace. All the patients were assessed at 3, 6, and 12 months using the diseasespecific Kujala scale and a visual analog scale (VAS) for pain; time to return to sport and patient satisfaction with the brace were also recorded.

Results Kujala scale's values showed constant and progressive improvement. The mean score at 6 months was $79.8 \pm 6.8$ points in group $A$ and $76.8 \pm 8.6$ in group $B$, rising at 12 months to $80.9 \pm 7.5$ in group $A$ and $78.4 \pm 8.3$ in group B. VAS scores significantly differed $(p<0.05)$ between the two groups at both 6 and 12 months; the score recorded at 12 months was $0.9 \pm 1.3$ in the brace-treated group and $1.8 \pm 1.6$ in the controls. The patients who used a brace showed a quicker return to sports and $75 \%$ of the patients in this group were satisfied.

Conclusion All the scores improved progressively in both groups. The most significant improvement concerned pain, showing that the brace used in this study may allow a better subjective outcome and a quicker return to sport.

Level of Evidence Level II, prospective randomized controlled trial.
\end{abstract}

\section{Introduction}

Anterior knee pain is currently one of the problems most frequently encountered in orthopaedic settings and one of the most difficult to manage. ${ }^{1,2}$ Retropatellar and peripatellar pain, clinically referred to as patellofemoral pain (PFP), is a common disorder experienced by young adult and adolescent athletes who participate in jumping, cutting, and pivoting sports. ${ }^{3-5}$ Prevalence of PFP seems to be higher in females. ${ }^{6,7}$ This is probably due to anatomical, neuromuscular, and hormonal factors. ${ }^{8}$

Patellofemoral disorders may be divided into three groups: objective patellar instability, potential patellar instability, and PFP. ${ }^{9}$ Pain is the main symptom of potential patellar instability, which is characterized by the presence of at least one of the main factors of instability, namely, trochlear dysplasia, patella alta, and pathological tibial tuberosity-trochlear groove distance. Pain is also the main received

October 22, 2017

accepted after revision

May 20, 2018

published online

June 22, 2018
DOI https://doi.org/

10.1055/s-0038-1661339.

ISSN 2282-4324.
Copyright (c) 2018 Georg Thieme Verlag License terms

KG Stuttgart · New York 
symptom of PFP syndrome (PFPS), in which the pain has a mainly nonpatellar origin (hip, ankle, spine, etc.). ${ }^{10,11}$

In the absence of chondral lesions, conservative treatment is usually the first option for the PFPS. This approach, based on an appropriate rehabilitation program, is designed to manage pain and promote recovery of the range of motion (ROM), as well as muscle strength and proprioception. ${ }^{12}$ Rehabilitation is often supported by the use of knee braces and foot orthoses. ${ }^{13}$

Knee braces have been shown to reduce pain by reducing patellofemoral pressure and increasing the contact area to allow a better distribution of the forces over the patellofemoral joint. ${ }^{2,12,14,15}$ Their effectiveness has been explored in several studies, with contrasting results. ${ }^{16-24}$

The purpose of this study was to assess the efficacy of a new knee brace with elastomeric properties specifically developed for athletes, in adjunct to a purposed rehabilitation program, in relieving symptoms in patients affected by PFPS. The hypothesis of the study was that the knee brace has a significant effect on symptoms relief in patients affected by PFPS.

\section{Methods}

This study was designed as a prospective randomized multicenter study. Seventy patients were recruited at the Knee Surgery Unit of the G. Pini Orthopaedic Institute in Milan and at the Orthopaedic Clinic of the University Hospital of Sassari. All the patients included were informed of the randomized nature of the study, and signed a purposed informed consent. The institutional review boards approved the study and all the procedures were in accordance with the current ethical standards.

Inclusion criteria were: age between 16 and 35 years, a diagnosis of anterior knee pain due to PFPS, a Tegner score of $\geq 3$, and a body mass index (BMI) between 18 and 26 . Patients with knee comorbidities, such as ligament, meniscus, or cartilage lesions, were excluded.

Patients were randomized into two groups. In group A, patients underwent a rehabilitation program combined with the use of a knee brace (Reaction Knee Brace; DJO Global, Vista, California, United States); in group B, they underwent only rehabilitation. The rehabilitation protocol was divided into different phases based on the patient's progress. The goal of the first phase was to reduce pain and swelling, to improve the balance between vastus medialis and vastus lateralis of the quadriceps muscle, to restore normal gait, and to decrease loading of the patellofemoral joint. The second phase included improvement of postural control and coordination of the lower extremity, increase of quadriceps and hip muscle strength, and restoration of good knee function. The patients were encouraged to return to sports with a suitable regular physical exercise. The third phase included functional exercises.

All the patients were assessed before treatment and again at 3,6 , and 12 months afterwards, using a specifically designed instrument for scoring patellofemoral disorders (Kujala scale $)^{25}$ and a pain visual analog scale (VAS). In addition, time to return to sport and subjective patient satisfaction at the end of treatment were also recorded.

A $2 \times 4$ univariate analysis of variance (ANOVA) explored the effect of the brace versus no braced conditions over the different time points using the baseline as a covariate for the Kujala score and pain VAS. Time effect, group effect, and time per group interaction were explored by the use of repeated measure ANOVA. Significance was set at $p$-value of $<0.05$.

\section{Results}

Following the exclusion of 10 patients who were lost during the study or at follow-up, data analysis included 60 patients (all nonprofessional athletes) ( $\mathbf{- F i g . 1}$ ). These comprised of 47 females and 13 males, with a mean age of $20 \pm 4$ years (range, 16-30 years) and a mean BMI of 23 (range, 18-26). The two groups did not show significant differences for age, gender, and BMI. - Table 1 shows the descriptive statistics for group A (knee brace used in combination with a rehabilitation program) and group $B$ (rehabilitation alone) at the different time points.

The mean Kujala score showed a constant and progressive improvement over the follow-up period. The mean score at 6 months was $79.8 \pm 6.8$ points (range, 66-95) in group A and $76.8 \pm 8.6$ points (range, 60-95) in group $B$, rising at 12 months to $80.9 \pm 7.5$ points (range, $70-100$ ) in group $A$ and $78.4 \pm 8.3$ points (range, 67-100) in group B.

Successive reductions were observed in the mean VAS score, which fell from a common value of $5.9 \pm 1.9$ points (range, 3-9) in both groups at baseline, to $1.4 \pm 1.5$ (range, $0-7$ ) in group A and $3 \pm 1.6$ (range, $0-6$ ) in group B at 6 months, and then to $0.9 \pm 1.3$ points (range, $0-5$ ) in group A and $1.8 \pm 1.6$ (range, $0-5$ ) in group B at 12 months (-Fig. 2).

At 6 months, 42 of the 60 patients returned to sports; 24 of these were from group $A$ and 14 from group B. Of the patients that used the brace, $75 \%$ declared that they were satisfied or very satisfied with it.

The mean Kujala score showed no significant differences between the two groups but did show significant differences between time points $(p<0.001)$. Further post hoc pairwise comparison testing showed significant differences between all time points showing continuous improvement in both groups up to 12 months (-Table $\mathbf{2}$ ).

Significantly lower mean pain VAS was seen in group A $(p<0.001)$ and between time points $(p<0.001)$. In addition, a significant interaction between the two factors was also seen $(p<0.001)$, and the repeated measures ANOVA performed separately on the two groups showed significant differences between all time points for both groups (-Table 3).

\section{Discussion}

The best therapeutic approach to anterior knee pain is conservative treatment consisting of the use of nonsteroidal anti-inflammatory drugs for short periods of time, together with targeted rehabilitation programs and the application of 


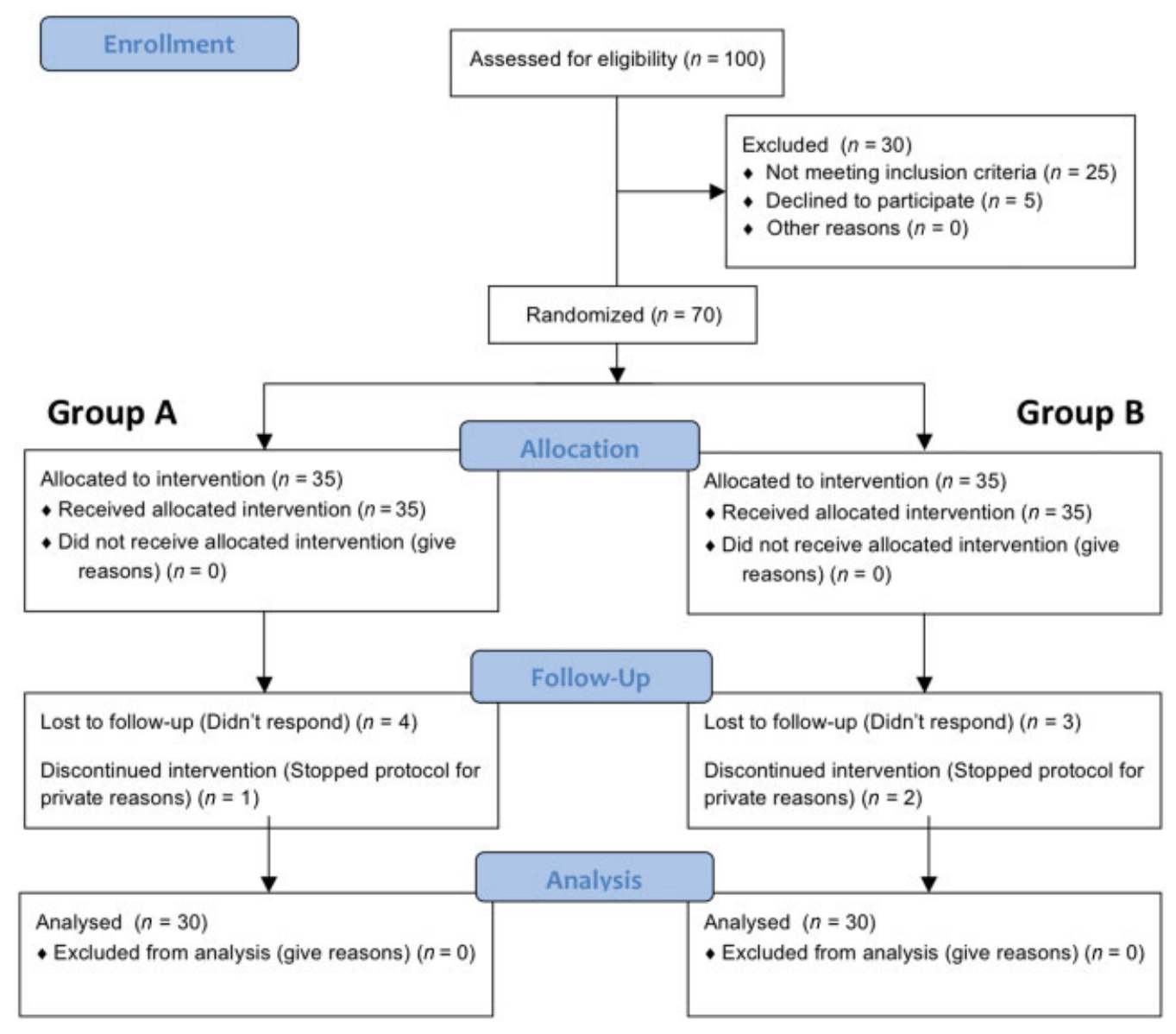

Fig. 1 Flow diagram of patients throughout the course of the study.

forces to restore medial alignment of the patella. ${ }^{11}$ The latter objective is mainly achieved through the use of taping and knee braces. ${ }^{12}$ The precise mechanism by which either of these solutions may be effective is not entirely known. The knee braces traditionally available on the market are mostly designed and constructed to apply an external, medially directed force that, in theory, counteracts the "maltracking" that tends to result in lateralization of the patella. Published

Table 1 Descriptive statistics for group A (knee brace used in combination with a rehabilitation program) and group $B$ (rehabilitation alone)

\begin{tabular}{|l|l|l|l|}
\hline Groups & Time interval & $\begin{array}{l}\text { Kujala score, } \\
\text { mean (SD) }\end{array}$ & $\begin{array}{l}\text { VAS score, } \\
\text { mean (SD) }\end{array}$ \\
\hline Group A & Baseline & $74.3(7.1)$ & $6.0(1.9)$ \\
\cline { 2 - 4 } & 3 months & $77.1(7.9)$ & $2.9(1.9)$ \\
\cline { 2 - 4 } & 6 months & $79.8(6.9)$ & $1.4(1.6)$ \\
\cline { 2 - 4 } & 12 months & $80.9(7.5)$ & $0.9(1.4)$ \\
\hline Group B & Baseline & $70.4(7.2)$ & $5.9(1.6)$ \\
\cline { 2 - 4 } & 3 months & $74.7(8.1)$ & $3.7(1.5)$ \\
\cline { 2 - 4 } & 6 months & $76.9(8.6)$ & $3.0(1.5)$ \\
\cline { 2 - 4 } & 12 months & $78.4(8.3)$ & $1.8(1.7)$ \\
\hline
\end{tabular}

Abbreviations: SD, standard deviation; VAS, visual analog scale. literature on the use of such braces is conflicting. ${ }^{23}$ Draper et al, ${ }^{19}$ in an magnetic resonance imaging study on females with PFP, demonstrated that a brace applying a medial load to the patella can reduce lateral translation of the patella and

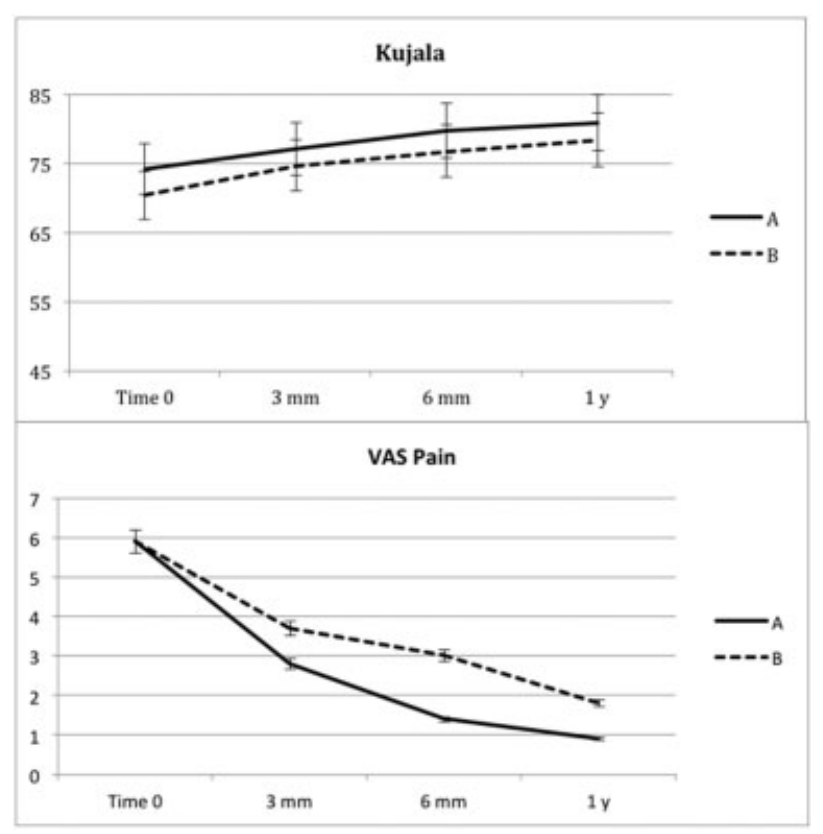

Fig. 2 Line diagrams of outcomes throughout the course of the study. 
Table 2 Pairwise comparisons of time points for Kujala scores

\begin{tabular}{|l|l|l|l|l|}
\hline Group A + B & $\begin{array}{l}\text { Mean } \\
\text { differences }\end{array}$ & $p$-Value & \multicolumn{2}{|l|}{$\begin{array}{l}\text { 95\% Cl of } \\
\text { difference }\end{array}$} \\
\hline Baseline vs. $3 \mathrm{mo}$ & -3.25 & $<0.001$ & -4.72 & -1.78 \\
\hline Baseline vs. $6 \mathrm{mo}$ & -5.75 & $<0.001$ & -7.22 & -4.28 \\
\hline Baseline vs. $12 \mathrm{mo}$ & -7.32 & $<0.001$ & -8.75 & -5.89 \\
\hline 3 vs. 6 mo & -2.50 & 0.001 & -4.01 & -0.99 \\
\hline 3 vs. $12 \mathrm{mo}$ & -4.07 & $<0.001$ & -5.54 & -2.60 \\
\hline 6 vs. 12 mo & -1.57 & 0.036 & -3.04 & -0.10 \\
\hline
\end{tabular}

Abbreviation: $\mathrm{Cl}$, confidence interval.

lateral tilt more effectively than a functional bandage can. Powers at $\mathrm{al}^{13}$ found improvement of pain and better activation of the quadriceps during ascending and descending stairs when using bracing. Further effects on knee joint biomechanics were studied by Selfe et al, ${ }^{22,26}$ who demonstrated improved coronal plane and torsional control of the knee during eccentric quadriceps contractions in subjects with soft knee braces. Thijs et $\mathrm{al}^{24}$ and Callaghan et $\mathrm{al}^{16}$ reported proprioceptive effects and increased motor neuron activity; the latter detected modulation of the supplementary motor area, the cingulate motor area, and other neural areas of the brain during a proprioception knee motor task performed with and without bracing and patellar taping, respectively. In addition, D'Hondt et $\mathrm{al}^{18}$ and Crossley et al ${ }^{17}$ performed meta-analyses that highlighted better outcomes in patients using knee braces, namely, reduced pain, improved function, and a lower patellofemoral congruence angle. However, these papers also underlined the poor quality of studies in this setting, also drawing attention to

Table 3 Pairwise comparisons of time points for VAS scores

\begin{tabular}{|c|c|c|c|c|}
\hline \multirow{2}{*}{$\begin{array}{l}\text { Group A } \\
\text { Baseline vs. } 3 \mathrm{mo}\end{array}$} & \multirow{2}{*}{$\begin{array}{l}\text { Mean } \\
\text { differences }\end{array}$} & \multirow{2}{*}{$\begin{array}{l}p \text {-Value } \\
<0.001\end{array}$} & \multicolumn{2}{|c|}{$\begin{array}{l}95 \% \mathrm{Cl} \text { of } \\
\text { difference }\end{array}$} \\
\hline & & & 2.81 & 3.80 \\
\hline Baseline vs. 6 mo & 4.61 & $<0.001$ & 4.01 & 5.20 \\
\hline Baseline vs. $12 \mathrm{mo}$ & 5.30 & $<0.001$ & 4.49 & 6.12 \\
\hline 3 vs. $6 \mathrm{mo}$ & 1.30 & 0.001 & 0.63 & 1.97 \\
\hline 3 vs. $12 \mathrm{mo}$ & 2.00 & $<0.001$ & 1.19 & 2.81 \\
\hline 6 vs. $12 \mathrm{mo}$ & 0.70 & 0.006 & 0.22 & 1.17 \\
\hline \multicolumn{5}{|l|}{ Group B } \\
\hline Baseline vs. $3 \mathrm{mo}$ & 2.16 & $<0.001$ & 1.79 & 2.53 \\
\hline Baseline vs. 6 mo & 2.84 & $<0.001$ & 2.49 & 3.19 \\
\hline Baseline vs. $12 \mathrm{mo}$ & 4.20 & $<0.001$ & 3.80 & 4.60 \\
\hline 3 vs. $6 \mathrm{mo}$ & 0.68 & 0.001 & 0.31 & 1.05 \\
\hline 3 vs. 12 mo & 2.04 & $<0.001$ & 1.62 & 2.46 \\
\hline 6 vs. $12 \mathrm{mo}$ & 1.36 & $<0.001$ & 0.92 & 1.80 \\
\hline
\end{tabular}

Abbreviations: $\mathrm{CI}$, confidence interval; VAS, visual analog scale. publications with limited level of evidence. ${ }^{27}$ Conflicting results may also be attributable to variations in orthosis/ brace designs used.

The knee brace used in this study implements an active approach that, in addition to controlling the vertical movement of the patella, ensures return of the kinetic energy accumulated during the specific sport-related flexion movement, thus lessening its impact forces. The brace features an anterior web-like structure made up of elastomeric bands that act like an elastic exoskeleton and, through elongation of the extensible components, attenuate the forces of impact on the joint, thus ensuring maintenance of proprioceptive contact throughout the entire ROM. The effect of web-like structure has been shown to improve knee stability during different sport-related motor tasks in healthy subjects, which has implications to the management of individuals with knee instability. ${ }^{20,28}$ Furthermore, during sports activities, the web-like structure claims to distribute the forces exerted more evenly on the patellofemoral joint and extensor mechanism.

The results of our study seem to indicate that this brace may be a useful aid in the treatment of anterior knee pain in amateur athletes, speeding up their return to sport and allowing better pain management.

Our results showed that the most significant improvement concerned pain, which was reduced by mean of over 5 VAS points, with a significant difference $(p<0.05)$ between the two groups in favor of the group who received knee bracing. We observed a progressive and significant improvement of all scores across all the time points in both the groups on VAS and Kujala scales. Moreover, 24 out of 30 patients in the group who received knee bracing returned to sport at 6 months, as opposed to only 14 of those who received the rehabilitation program only. This demonstrated that the rehabilitation program appears to be more effective when combined with the use of brace. Furthermore, $75 \%$ of the patients with brace were satisfied with the treatment, thus confirming the good level of compliance with the use of brace.

Our study has several limitations. No comparison was made with other types of brace; the sample of patients studied was small and they practiced different types of sport. All of these factors could potentially have biased our results.

In conclusion, the results of this study showed that the Reaction Knee Brace may be an effective adjunct to reducing pain in individuals with anterior knee pain and for speeding up their return to sport. As with taping, ${ }^{29}$ the mechanisms by which these benefits are obtained remain unclear; they could be linked to a redistribution of stress forces, increased proprioceptive inputs, and increased neuromuscular control, which may be facilitated by the web-like structure of the knee brace and then may produce better quadriceps activation and greater control over the execution of sports exercises. Further biomechanical and clinical studies are needed to investigate more in-depth the mechanisms underlying the effectiveness of such devices and their role in rehabilitation. 


\section{Conflict of Interest}

None.

\section{References}

1 Davis IS, Powers CM. Patellofemoral pain syndrome: proximal, distal, and local factors, an international retreat, April 30-May 2, 2009, Fells Point, Baltimore, MD. J Orthop Sports Phys Ther 2010; 40(03):A1-A16

2 Saubade M, Martin R, Becker A, Gremion G. Patellofemoral pain syndrome: understand better in order to treat better [in French]. Rev Med Suisse 2014;10(437):1451-1456

3 Calmbach WL, Hutchens M. Evaluation of patients presenting with knee pain: part I. History, physical examination, radiographs, and laboratory tests. Am Fam Physician 2003;68(05): 907-912

4 Fagan V, Delahunt E. Patellofemoral pain syndrome: a review on the associated neuromuscular deficits and current treatment options. Br J Sports Med 2008;42(10):789-795

5 Myer GD, Ford KR, Barber Foss KD, et al. The incidence and potential pathomechanics of patellofemoral pain in female athletes. Clin Biomech (Bristol, Avon) 2010;25(07):700-707

6 Boling M, Padua D, Marshall S, Guskiewicz K, Pyne S, Beutler A. Gender differences in the incidence and prevalence of patellofemoral pain syndrome. Scand J Med Sci Sports 2010;20(05): 725-730

7 Willson JD, Davis IS. Utility of the frontal plane projection angle in females with patellofemoral pain. J Orthop Sports Phys Ther 2008; 38(10):606-615

8 Robinson RL, Nee RJ. Analysis of hip strength in females seeking physical therapy treatment for unilateral patellofemoral pain syndrome. J Orthop Sports Phys Ther 2007;37(05):232-238

9 Berruto M, Ferrua P, Carimati G, Uboldi F, Gala L. Patellofemoral instability: classification and imaging. Joints 2013;1(02):7-14

10 Dejour H, Walch G, Nove-Josserand L, Guier C. Factors of patellar instability: an anatomic radiographic study. Knee Surg Sports Traumatol Arthrosc 1994;2(01):19-26

11 Petersen W, Ellermann A, Gösele-Koppenburg A, et al. Patellofemoral pain syndrome. Knee Surg Sports Traumatol Arthrosc 2014; 22(10):2264-2274

12 McCarthy MM, Strickland SM. Patellofemoral pain: an update on diagnostic and treatment options. Curr Rev Musculoskelet Med 2013;6(02):188-194

13 Powers CM, Ward SR, Chen YJ, Chan LD, Terk MR. Effect of bracing on patellofemoral joint stress while ascending and descending stairs. Clin J Sport Med 2004;14(04):206-214

14 Ghasemi MS, Dehghan N. The comparison of Neoprene palumbo and Genu direxa stable orthosis effects on pain and activity of daily living in patients with patellofemoral syndrome: a randomized blinded clinical trial. Electron Physician 2015;7(06): 1325-1329

15 Sinclair JK, Selfe J, Taylor PJ, Shore HF, Richards JD. Influence of a knee brace intervention on perceived pain and patellofemoral loading in recreational athletes. Clin Biomech (Bristol, Avon) 2016;37:7-12

16 Callaghan MJ, McKie S, Richardson P, Oldham JA. Effects of patellar taping on brain activity during knee joint proprioception tests using functional magnetic resonance imaging. Phys Ther 2012;92 (06):821-830

17 Crossley K, Bennell K, Green S, McConnell J. A systematic review of physical interventions for patellofemoral pain syndrome. Clin J Sport Med 2001;11(02):103-110

18 D'hondt NE, Struijs PA, Kerkhoffs GM, et al. Orthotic devices for treating patellofemoral pain syndrome. Cochrane Database Syst Rev 2002;1(02):CD002267

19 Draper CE, Besier TF, Santos JM, et al. Using real-time MRI to quantify altered joint kinematics in subjects with patellofemoral pain and to evaluate the effects of a patellar brace or sleeve on joint motion. J Orthop Res 2009;27(05):571-577

20 Hanzlíková I, Richards J, Tomsa M, et al. The effect of proprioceptive knee bracing on knee stability during three different sport related movement tasks in healthy subjects and the implications to the management of Anterior Cruciate Ligament (ACL) injuries. Gait Posture 2016;48:165-170

21 Selfe J, Janssen J, Callaghan M, et al. Are there three main subgroups within the patellofemoral pain population? A detailed characterisation study of 127 patients to help develop targeted intervention (TIPPs). Br J Sports Med 2016;50(14):873-880

22 Selfe J, Richards J, Thewlis D, Kilmurray S. The biomechanics of step descent under different treatment modalities used in patellofemoral pain. Gait Posture 2008;27(02):258-263

23 Smith TO, Drew BT, Meek TH, Clark AB. Knee orthoses for treating patellofemoral pain syndrome. Cochrane Database Syst Rev 2015; 12(12):CD010513

24 Thijs Y, Vingerhoets G, Pattyn E, Rombaut L, Witvrouw E. Does bracing influence brain activity during knee movement: an fMRI study. Knee Surg Sports Traumatol Arthrosc 2010;18(08): 1145-1149

25 Kujala UM, Jaakkola LH, Koskinen SK, Taimela S, Hurme M, Nelimarkka O. Scoring of patellofemoral disorders. Arthroscopy 1993;9(02):159-163

26 Selfe J, Thewlis D, Hill S, Whitaker J, Sutton C, Richards J. A clinical study of the biomechanics of step descent using different treatment modalities for patellofemoral pain. Gait Posture 2011;34 (01):92-96

27 Warden SJ, Hinman RS, Watson MA Jr, Avin KG, Bialocerkowski AE, Crossley KM. Patellar taping and bracing for the treatment of chronic knee pain: a systematic review and meta-analysis. Arthritis Rheum 2008;59(01):73-83

28 Harput G, Ulusoy B, Ozer H, Baltaci G, Richards J. External supports improve knee performance in anterior cruciate ligament reconstructed individuals with higher kinesiophobia levels. Knee 2016; 23(05):807-812

29 Hinman RS, Crossley KM, McConnell J, Bennell KL. Efficacy of knee tape in the management of osteoarthritis of the knee: blinded randomised controlled trial. BMJ 2003;327(7407):135 